\title{
O exame nacional de desempenho dos estudantes de Química: análise comparativa entre iniciantes e concluintes
}

The national examination of students' performance in chemistry: comparative analysis between beginners and undergraduates

\author{
Edenilza Mendonça de Santana ${ }^{1}$ \\ Edson José Wartha ${ }^{2}$ \\ Murilo de Medeiros Sampaio ${ }^{3}$
}

\section{Resumo}

Este artigo faz uma classificação e análise das questões objetivas de formação geral do ENADE-2014 com base na taxonomia do pensamento crítico. A partir desta classificação, trabalhou-se com a variável de desempenho, correspondente às notas obtidas pelos estudantes nas questões, relacionando-a com outras três variáveis independentes: i) curso (bacharelado e licenciatura, considerando estudantes ingressantes e concluintes); ii) instituição (pública ou privada) e iii) escola (pública ou privada). $\mathrm{Na}$ análise destes pares empregou-se o teste de qui-quadrado a fim de identificar qual variável é mais relevante para o desempenho dos estudantes em questões que possivelmente demandam capacidades do pensamento crítico. Verificou-se que as questões de formação geral objetivas demandam capacidades do pensamento crítico para a sua resolução e que na variável curso, os estudantes concluintes de ambos cursos apresentam desempenho superior, na variável instituição, quando os estudantes são pertencentes a IES privadas, os estudantes concluintes da licenciatura apresentam um desempenho superior, já quando os estudantes são de IES públicas, os ingressantes apresentam um maior destaque no desempenho. Na variável escola, os estudantes de escolas públicas demonstram melhor desempenho quando são concluintes. Os estudantes que vieram de escolas privadas apresentam um desempenho superior quando são ingressantes.

Palavras chave: pensamento crítico; testes de desempenho; competências e habilidades.

\section{Abstract}

This article aims a classification and analysis of the general training objectives of ENADE-2014 based on the taxonomy of critical thinking. From this classification, we worked with the performance variable, corresponding to the grades obtained by the students in the questions, relating it to three other independent variables: i) course

\footnotetext{
${ }^{1}$ Universidade Federal de Sergipe | denny.ems@gmail.com

${ }^{2}$ Universidade Federal de Sergipe | ejwartha@gmail.com

${ }^{3}$ Universidade Federal de Sergipe |xmurilo@yahoo.com.br
} 
(bachelor and licentiate, considering entrants and graduates students); ii) institution (public or private) and iii) school (public or private). In the analysis of these pairs, the chi-square test was used in order to identify which variable is most relevant for the students' performance in questions that possibly demand critical thinking skills. It was verified that the questions general formation objective demand critical thinking skill for their resolution and that in the course variable, the graduate students of both courses, present superior performance in the variable institution. When the students belong to private IES, the student's graduates present a superior performance, when students are from public IES, the students present a greater prominence in performance. In the school variable, public school students demonstrate better performance when they are graduate students. Students who have come from private schools perform better when they are beginner students.

Keywords: critical thinking; performance testing; skills and abilities.

\section{Introdução}

Os sistemas de avaliação em larga escala, desenvolvidos por órgãos governamentais, buscam levantar informações sobre a eficiência e a qualidade das instituições que provem bens públicos à população. Tais informações são fundamentais para uma melhor gestão dos recursos públicos, visto que permitem visualizar virtudes e falhas do sistema para que ações interventivas e regulatórias sejam criadas com objetivo amplo de melhorar a qualidade do sistema (PRIMI, 2006).

Especialmente no que diz respeito ao sistema educacional brasileiro, nas últimas duas décadas, observa-se que o Ministério da Educação (MEC) tem colocado a avaliação como um alvo importantes de suas políticas. A partir de 1990, do século passado, vários sistemas de avaliação, do Ensino Fundamental (Sistema de Avaliação do Ensino Básico - SAEB), Ensino Médio (Exame Nacional do Ensino Médio - ENEM) e Ensino Superior (Exame Nacional de Cursos - ENC e, recentemente, o Sistema Nacional de Avaliação do Ensino Superior - SINAES) do qual o ENADE (Exame Nacional de Desempenho de Estudantes) faz parte, são organizados e geridos pelo MEC através do INEP (Instituto Nacional de Estudos e Pesquisas Educacionais Anísio Teixeira).

O ENADE foi criado em 2004, pela Lei n. 10.861, com o objetivo de avaliar o processo de ensino-aprendizagem dos cursos de graduação no Brasil (BRASIL, 2004) em substituição ao ENC (Exame Nacional de Cursos), antigo "Provão". O ENADE é um exame obrigatório, aplicado trienalmente para os cursos de nível superior de todo o Brasil como parte integrante do SINAES. O objetivo é avaliar o desempenho dos estudantes com relação aos conteúdos programáticos previstos nas diretrizes curriculares dos cursos de graduação, o desenvolvimento de competências e habilidades necessárias ao aprofundamento da formação geral e profissional, e o nível de atualização dos estudantes com relação à realidade nacional e internacional (BRASIL, 2004).

Primi et al. (2010) questionam se o ENADE tem relação com a prova propriamente dita, isto é, seu conteúdo. Questionam se, da forma como são elaboradas e aplicadas as questões, estas são eficazes em avaliar as competências profissionais e habilidades acadêmicas conforme planejado e, quais os parâmetros referenciais para sua interpretação. Argumentam e questionam se é possível avaliar a qualidade de um curso baseados em uma 
prova, ou seja, a questão crucial se relaciona diretamente com a qualidade dos instrumentos.

O exame é composto pelos componentes de formação geral (duas questões discursivas e oito objetivas), pelos componentes específicos (três questões discursivas e dezessete objetivas) e um questionário de percepção de prova (composto por nove questões). As questões da componente de formação geral do ENADE propõem-se a relevar elementos integrantes do perfil do futuro profissional, buscando ressaltar aspectos como a atitude ética, comprometimento social, espírito científico, humanístico e reflexivo e capacidade de pensar e analisar criticamente aspectos reais ou hipotéticos. Além desses elementos, essas questões pretendem verificar habilidades e competências dos estudantes ingressantes e concluintes que vão das funções básicas de leitura e interpretação, até a capacidade de resolução de problemas de maneira crítica (BRASIL, 2014).

$\mathrm{Na}$ avaliação do desempenho do ENADE as medidas são transversais, ou seja, são compostas de amostras de estudantes ingressantes e concluintes no mesmo ano. Assim, assumindo-se que o nível de desempenho dos concluintes era na época em que ingressaram, similar ao desempenho dos alunos ingressantes no ano corrente. Assim, a diferença das médias entre ingressantes e concluintes, ainda que obtidas no mesmo ano, são tidas como um indicador de mudança entre estes dois níveis. Portanto, no ENADE, se tem uma comparação de ingressantes e concluintes no nível do curso e não do aluno. Como o estudo não é longitudinal, o ENADE tenta realizar uma aproximação de uma medida da qualidade de curso no cálculo do Indicador de Diferença entre os Desempenhos Observados e Esperados (IDD). O IDD tem o propósito de trazer às instituiç̧̃es informações comparativas dos desempenhos de seus estudantes concluintes em relação aos resultados obtidos, em média, pelas demais instituições cujos perfis de seus estudantes ingressantes são semelhantes.

Como O ENADE pretende avaliar conhecimentos, competências e habilidades acadêmicas desenvolvidas ao longo do curso, por meio de testes compostos por itens que operacionalizam medidas em diferentes níveis de complexidade de uma dimensão latente, que quando agregados, permitem estimar a habilidade de uma pessoa nessa dimensão. Assim, o objetivo deste estudo é realizar uma análise comparativa entre os ingressantes e concluintes dos cursos de química que realizaram o ENADE no ano de 2014 apenas nas questões de conhecimentos gerais, visto que estas questões podem fornecer alguns indicativos de como os cursos de química estão desenvolvendo capacidades de pensamento crítico nos discentes.

A formação de profissionais deve estar voltada para uma educação emancipatória e permanente, garantindo o desenvolvimento de estudantes com condições para o exercício do Pensamento Crítico (PC), que é defendido também como objetivo da educação superior nas diretrizes curriculares das licenciaturas, apresentadas na resolução $n^{\circ} 2$, de $1^{\circ}$ de julho de 2015 (BRASIL, 2015) quando ressalta que:

[...] às dinâmicas pedagógicas que contribuam para o exercício profissional e o desenvolvimento do profissional do magistério por meio de visão ampla do processo formativo, seus diferentes ritmos, tempos e espaços, em face das dimensões psicossociais, histórico-culturais, afetivas, relacionais e interativas que permeiam a ação pedagógica, possibilitando as condições para o exercício do pensamento crítico, a resolução de problemas, o trabalho coletivo e interdisciplinar, a criatividade, a inovação, a liderança e a autonomia. (BRASIL, 2015, p. 6) 
As pesquisas sobre Pensamento Crítico ( $P C$ ) abrangem diversas áreas acadêmicas especialmente nos Estados Unidos e na Europa, com ênfase em Portugal, onde há um grupo de pesquisa voltado às temáticas relacionadas ao Pensamento Crítico, como construção de materiais didáticos que propiciam o desenvolvimento de capacidades de pensamento crítico, estratégias de ensino promotoras do PC, formação de professores com orientações do PC, PC e CTS, entre outros tópicos.

Pensar criticamente é essencial, não apenas para os estudantes, mas também para todas as pessoas da sociedade que pretendem desempenhar um papel ativo e consciente, pois, espera-se que todos possam pensar por si próprios e executar uma variedade de tarefas, identificando e resolvendo os problemas que surgem, trabalhando sempre em colaboração com outras pessoas para a solução dos problemas. Para além deste fato, num ambiente tecnológico em constante mudança, torna-se difícil, se não impossível, prever qual o conhecimento que os estudantes virão necessitar no futuro. Além disso, pensar criticamente, faz com que estudantes possam ir além ao que se refere a aprender um determinado conhecimento, fazendo com que ele desempenhe um papel reflexivo sobre a natureza do conhecimento, sendo capaz de estabelecer relações entre as áreas de conhecimento. (VIEIRA, 2014; COLE, et al., 2015)

Pensar criticamente é importante, pois, na maior parte das situações da vida o conhecimento nunca é completo, então é necessário pensar. Ao invés de se desenvolver a capacidade dos estudantes de memorizarem ou relembrarem, deve surgir à capacidade de definir problemas, selecionar informações e resolver problemas de forma flexível, levando o estudante a aprender de forma autônoma, tendo a capacidade de rever ideias e sintetizar informações. (TENREIRO-VIEIRA; VIEIRA, 2001; VIEIRA, 2000)

Como consequência de tais fatos, o pensamento crítico é considerado, por muitos investigadores e educadores, como um objetivo educacional prioritário. No entanto, as salas de aula, em sua maioria, continuam a expor os estudantes a grandes quantidades de informações que devem ser memorizadas. Os questionamentos realizados pelos professores não criam oportunidades para que os estudantes discutam ideias e debatam pontos de vista. Grande parte dos questionamentos são focados na repetição dos conhecimentos que são transmitidos, fazendo da educação um monólogo destinado a partilhar "bits" de informação na mente dos estudantes. Entretanto, a educação e o ensino de ciências devem propiciar o explícito treino de capacidades do pensamento crítico, que abrem novas perspectivas ao estudante e o torna capaz de aprender racionalmente. Esta via permite-Ihes analisar, decidir aquilo que é verdadeiro, dominar e controlar o seu próprio conhecimento e adquirir novo conhecimento (VIEIRA, 2001).

Dentre as definições conhecidas sobre o PC, a de maior destaque e uso, é a apresentada por Ennis (1985), segundo esse autor, O PC surge geralmente em atividades que requerem reflexão e ação, e é definido como: "(...) uma forma de pensamento racional, reflexivo, focado no que decidir em que acreditar ou o que fazer" (ENNIS, 1985, p. 46), ou seja, é um pensamento exercitado por meio de uma reflexão para uma ação, que ocorre dentro de um contexto que requer a solução de um problema que muitas vezes promove a interação entre pessoas (TENREIRO-VIEIRA; VIEIRA, 2000).

O PC envolve capacidades e disposições, em que as capacidades estão associadas ao potencial de um indivíduo para pensar, aprender ou realizar uma tarefa e se referem aos aspectos cognitivos. Já as disposições estão relacionadas aos aspectos mais afetivos, a ação, a predisposição a algo, ao comportamento, por exemplo. As capacidades cognitivas estão 
relacionadas a um determinado conjunto de habilidades cerebrais necessárias para se obter conhecimento sobre o mundo, envolvendo pensamento, raciocínio, abstração, linguagem, memória, criatividade e capacidade de resolução de problemas. (VIEIRA, 2003)

Essas capacidades estão organizadas na "Taxonomia do Pensamento Crítico de Ennis" e resumidamente divididas nas seguintes áreas de capacidades: a) clarificação elementar, b) suporte básico, c) inferência, d) clarificação elaborada, e) estratégias e táticas, que por sua vez estão subdivididas em doze áreas de capacidades: 1) focar uma questão, 2) analisar argumentos, 3) fazer e responder a questões de esclarecimento e desafio, 4) avaliar a credibilidade de uma fonte, 5) fazer e avaliar observações, 6) fazer e avaliar deduções, 7) fazer e avaliar induções, 8) fazer e avaliar juízos de valor, 9) definir termos e avaliar definições, 10) identificar assunções, 11) decidir sobre uma ação e 12) interatuar com os outros.

Quadro 1. Relação entre competências e habilidades do ENADE e as áreas de capacidades de PC.

\begin{tabular}{|c|c|}
\hline $\begin{array}{l}\text { Competências } \\
\text { e habilidades } \\
\text { (ENADE) }\end{array}$ & $\begin{array}{l}\text { Área de capacidades de Pensamento Crítico: aspectos que indicam as } \\
\text { aproximações entre Competências e habilidades (ENADE) }\end{array}$ \\
\hline 1 & Inferência: aproximação quando se trata de efetuar a interpretação de questões, enunciados; \\
\hline 2 & $\begin{array}{l}\text { Inferência: nesse caso está relacionada a capacidade do estudante de fazer e avaliar } \\
\text { deduções e/ou induções; }\end{array}$ \\
\hline 3 & $\begin{array}{l}\text { Inferência: fazer e avaliar deduções, formulando hipóteses, explicando evidências, } \\
\text { investigando, atribuindo juízo de valor as diferentes situações; } \\
\text { Clarificação elaborada: saber identificar e lidar com equívocos, tendo uma atenção ao } \\
\text { contexto, formulando respostas apropriadas; }\end{array}$ \\
\hline 4 & $\begin{array}{l}\text { Estratégias e táticas: a semelhança é identificada quando é mencionado que, diante de um } \\
\text { problema, o estudante deve rever, rendo em conta a situação no seu todo, e decidir, fazer } \\
\text { uma escolha, controlando assim o processo de tomada de decisão; } \\
\text { Inferência: atribuir juízo de valor na tomada de decisões; }\end{array}$ \\
\hline 5 & $\begin{array}{l}\text { Estratégias e táticas: para que possa argumentar coerentemente é necessário que o } \\
\text { estudante selecione critérios para determinados problemas, formule possíveis soluções e } \\
\text { para isso é necessário que ele sempre procure se manter bem informado; }\end{array}$ \\
\hline 6 & $\begin{array}{l}\text { Estratégias e táticas: o estudante deve decidir sobre uma ação, podendo interagir com os } \\
\text { demais para que tome decisões apropriadas; } \\
\text { Inferência: fazer e avaliar deduções, formular hipóteses, explicando evidências, investigando, } \\
\text { atribuindo juízo de valor as situações; }\end{array}$ \\
\hline 7 & $\begin{array}{l}\text { Estratégias e táticas: defina o problema, apresente soluções, selecione critérios para avaliar } \\
\text { possíveis soluções, formule soluções alternativas, decida o que fazer e controle a tomada de } \\
\text { decisões; } \\
\text { Inferência: é necessário também que ele seja capaz de formular e explicar hipóteses, fazes } \\
\text { generalizações e ser plausível; } \\
\text { Clarificação elaborada: além de tudo, deve ter a habilidade de identificar e lidar com } \\
\text { equívocos; }\end{array}$ \\
\hline 8 & $\begin{array}{l}\text { Clarificação elementar: está relacionada a analisar argumentos, tendo a capacidade de } \\
\text { resumi-los; }\end{array}$ \\
\hline 9 & $\begin{array}{l}\text { Estratégias e táticas: nesse caso há aproximação, pois faz-se necessário decidir sobre ações } \\
\text { para definir um problema, formular soluções alternativas, decidir o que fazer e interagir com } \\
\text { os outros. }\end{array}$ \\
\hline
\end{tabular}

\footnotetext{
4 É válido ressaltar que cada área possui uma série de significados e descrições (observar a descrição completa na pesquisa desenvolvida por VIEIRA e VIEIRA (2005)), mas para a construção desse quadro, foram utilizadas apenas as que estão associadas de alguma maneira com as competências e habilidades nas questões do ENADE.
} 
No ano de 2014 o INEP publicou a portaria para as questões de formação geral do ENADE-2014, nela são apresentadas as nove competências e habilidades que são cobradas nas questões de formação geral, aplicadas na avaliação de todos os cursos do Brasil (1. Ler, interpretar e produzir textos; 2. Extrair conclusões por indução e/ou dedução; 3. Estabelecer relações, comparações e contrastes em diferentes situações; 4. Fazer escolhas valorativas avaliando consequências; 5. Argumentar coerentemente; 6. Projetar ações de intervenção; 7. Propor soluções para situações-problema; 8. Elaborar sínteses; 9. Administrar conflitos.). É possível estabelecer relações entre essas competências e habilidades com as capacidades pertencentes a Taxonomia do Pensamento Crítico, assim como está descrito no quadro 1, em que estão enumeradas as 9 competências e habilidades do ENADE, seguidas da relação que pode ser estabelecida entre elas e as áreas que compõe a taxonomia do Pensamento Crítico.

Estabelecendo esta relação, buscou-se efetuar a classificação das questões objetivas do ENADE-2014 de acordo com a taxonomia do pensamento crítico de Ennis e, a partir de então, trabalhar com três variáveis de desempenho: i) relacionando-as ao curso (bacharelado e licenciatura, considerando estudantes ingressantes e concluintes); ii) tipo de instituição do curso (pública ou privada) e iii) tipo de escola de formação do aluno (pública ou privada). Empregou-se o teste de qui-quadrado para a análise desses pares, a fim de identificar qual variável é mais relevante para o desempenho dos estudantes em questões que possivelmente demandam capacidades do pensamento crítico.

\section{Abordagem Metodológica}

Este estudo analisou os dados do banco de dados do ENADE-2014 de Química. O banco contém uma amostra representativa de 3532 estudantes de química, sendo estudantes de química licenciatura ( $N=2206)$, estes divididos em ingressantes ( $N=381)$ e concluintes $(N=1825)$ e estudantes de química bacharelado $(N=1326)$, divididos em ingressantes ( $N=179)$ e concluintes $(N=1147)$ de todas as regiões do país. Desses, 2549 são de intuições públicas e 974 de instituições privadas, sendo que 1147 são oriundos de escolas públicas e 1093 de escolas privadas.

O estudo foi desenvolvido em três etapas:

Etapa 7: Construção dos quadros de classificação das questões objetivas e discursivas de formação geral do ENADE realizado no ano de 2014. Nesta etapa, foram selecionadas as questões que passariam pelo processo de classificação, que são aquelas que se enquadram no componente de formação geral, considerando apenas as questões objetivas da prova. As questões foram organizadas na tabela de classificação de questões para que pudessem ser classificadas e validadas de acordo com as capacidades de PC, para tal classificação, foi realizada uma adaptação do material desenvolvido por Tenreiro-Vieira e Vieira (2000). 0 material foi enviado para um conjunto de colaboradores de duas maneiras, a primeira delas de forma impressa, com a devolução da tabela de classificação preenchida na semana subsequente e na segunda, via e-mail, com o tempo de envio da tabela de classificação preenchida no período estipulado pelo pesquisador (15 dias). Alguns dos pesquisadores que efetuaram a classificação das questões estão vinculados a grupos de pesquisa que desenvolvem trabalhos na linha do PC, outros participaram de uma disciplina com temáticas relacionadas ao tema. É valido ressaltar que a escolaridade dos colaboradores varia de graduandos a doutores. 
Etapa 2: Análise da classificação dada pelos colaboradores. Os dados coletados foram organizados em planilhas e contabilizados para que se pudesse estabelecer um percentual de concordância na classificação dada pelos colaboradores, para tal, foi calculada uma porcentagem sobre a média dos dados encontrados para a classificação das questões presentes no estudo, para as doze áreas de capacidade do PC:

$$
P M C_{n}=\frac{n^{\circ} R Q_{n}}{n^{\underline{a} T A}} \times 100 \%
$$

Em que: $n^{\mathrm{o}} R Q_{n}=$ número de respostas para a questão, com $Q_{n}$ variando da $1^{\mathrm{a}}$ a $10^{\mathrm{a}}$ questão; $n^{\mathbf{a}} T A=$ número total da amostra; $P M C_{n}=$ percentual da marcação da capacidade, variando da $1^{\mathrm{a}}$ capacidade até a $12^{\mathrm{a}}$.

Após a identificação dos percentuais referentes a cada questão e a cada capacidade, utilizou-se uma adaptação do referencial de Nunez et al., (2005) para atribuir o percentual da marcação da capacidade, identificando a concordância entre as respostas dos colaboradores. A partir desse índice, seria atribuída a grande probabilidade, ou não de se haver a presença de determinada capacidade na questão. A partir da adaptação do referencial (Nunez et al., (2005)), consideramos os percentuais iguais ou superiores a 60\% como um bom percentual de marcação de capacidade, o que corresponde a grande probabilidade de haver a capacidade referida na questão.

Etapa 3: Construção do banco de dados e análise do desempenho dos estudantes. $\bigcirc$ INEP disponibiliza em sua plataforma, o banco de microdados de todos os anos de aplicação do ENADE para consultas e pesquisas. Os microdados são disponibilizados de maneira totalmente aberta, gratuita e com total acesso às informações, podendo qualquer pessoa fazer o download e efetuar a análise e tratamento dos dados. Em virtude de os dados serem disponibilizados de maneira conjunta, para todo o Brasil, o banco de dados é extenso e por conta disso, faz-se necessária a utilização de um software estatístico para que os dados possam ser filtrados de maneira mais simples, sem que seja necessário o uso de uma máquina potente para a edição e abertura do banco de microdados.

Na presente pesquisa, foi utilizado o software estatístico Statistical Package for the Social Scienses (SPSS) ${ }^{*}$, que é um software desenvolvido para a utilização por parte de profissionais das áreas de ciências exatas e humanas (OLIVEIRA, 2007). O INEP fornece imputs para os programas estatísticos SPSS e SAS.

Os bancos de dados analisados apresentaram algumas falhas na sua construção, falhas essas que foram corrigidas com o auxílio do SPSS para que se pudesse efetuar as análises, o banco de dados da prova de química foi editado separadamente, sendo realizada a filtragem do mesmo, de modo que apenas as variáveis de interesse para a pesquisa permanecessem no banco de dados. Permaneceram no banco de dados variáveis referentes ao código do grupo (código da área de enquadramento do curso no ENADE), região de funcionamento do curso, código do município de funcionamento do curso, idade do inscrito, sexo, o indicador de iniciante e concluinte, os tipos de presença dos estudantes nas questões de formação geral discursivas e objetivas, sendo considerados apenas aqueles que estiveram presentes em todas as questões, gabarito oficial da prova, gabarito de escolha dos estudantes (resposta dos estudantes na prova), notas das questões discursivas, que em todas as provas variam de 0 a 100 pontos e questionário socioeconômico para eventuais análises futuras.

* Licença: 10101151124 
O software R (64-bit), foi utilizado para realizar os testes de confiabilidade dos dados, para que fosse possível identificar a significância dos desempenhos apresentados pelos alunos. Com os bancos de dados organizados, deu-se início às análises do desempenho dos estudantes, criando tabelas de referência cruzada a fim de identificar o desempenho apresentado pelos estudantes tanto ingressantes, quanto concluintes, dos cursos de licenciatura e bacharelado em química, nas questões objetivas de formação geral da prova do ENADE-2014. Em seguida, com o auxílio do mesmo software foi realizado o teste de Qui-quadrado, para identificar se há diferença estatística significativa entre os desempenhos apresentados. Além da análise realizada com os dados referentes aos estudantes ingressantes e concluintes dos cursos de licenciatura e bacharelado, foram analisados dados relacionados aos estudantes pertencentes a instituições de nível superior públicas e privadas e também, com estudantes vindos de escolas públicas e privadas.

\section{Resultados}

A questão central investigada nas análises, era se havia diferenças significativas nos subgrupos de alunos ingressantes e concluintes pertencentes aos cursos de bacharelado e licenciatura em química (variável curso), quando provenientes de IES públicas e privadas (variável instituição), e oriundos de escolas púbicas e privadas (variável escola). Levando-se em consideração o desempenho dos estudantes em questões objetivas de formação geral do ENADE-2014.

De acordo com a Portaria INEP no 255 (BRASIL, 2014), as questões que fazem parte do componente de formação geral, pretendem verificar dez habilidades e competências que estão relacionadas à: I - ler, interpretar e produzir textos; II - extrair conclusões por indução e/ou dedução; III - estabelecer relações, comparações e contrastes em diferentes situações; IV - fazer escolhas valorativas avaliando consequências; V - argumentar coerentemente; VI projetar ações de intervenção; VII - propor soluções para situações-problema; VIII - elaborar sínteses; IX - administrar conflitos. Quando comparamos tais competências e habilidades com as áreas do PC e suas especificações, pode-se identificar que as mesmas apresentam semelhanças em vários aspectos. Assim, as questões de formação geral podem ser, também, classificadas de acordo com as áreas de capacidades de PC.

As doze áreas de capacidades do PC estão relacionadas de maneira geral a focar uma questão, analisar argumentos, fazer e responder a questões de esclarecimento e desafio, avaliar a credibilidade de uma fonte, fazer e avaliar observações, fazer e avaliar deduções, fazer e avaliar induções e fazer e avaliar juízos de valor, definir termos e avaliar definições, identificar assunções, decidir sobre uma ação e interatuar com os outros.

Na tabela 1 pode-se identificar as capacidades do pensamento crítico que estão presentes em cada uma das 8 questões. Assim como foi descrito na metodologia, foram consideradas como capacidades com grande probabilidade de serem desenvolvidas na questão, aquelas que apresentaram índice de concordância igual ou superior a 60\%, tais percentuais estão representados na tabela por um " $x$ ". As questões (RQ3-RQ10) estão relacionadas as questões de formação geral objetiva da prova ENADE-2014. 
Tabela 1. Representação das capacidades consideradas presentes nas questões de formação geral objetiva ENADE-2014.

\begin{tabular}{|c|c|c|c|c|c|c|c|c|}
\hline & RQ3 & RQ4 & RQ5 & RQ6 & RQ7 & $\mathrm{RQ8}$ & RQ9 & RQ10 \\
\hline CCPC 1 & $x$ & . & $x$ & . & . & $x$ & $x$ & . \\
\hline CCPC 2 & $x$ & . & $x$ & $x$ & $x$ & $x$ & $x$ & $x$ \\
\hline CCPC 3 & . & . & . & . & . & . & . & . \\
\hline CCPC 4 & $x$ & . & $x$ & . & . & . & 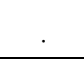 & . \\
\hline CCPC 5 & . & . & . & . & . & . & & . \\
\hline CCPC 6 & $x$ & $x$ & $x$ & . & $x$ & $x$ & $x$ & . \\
\hline CCPC 7 & . & . & . & . & . &. &. &. \\
\hline CCPC 8 & $x$ & . & . & . & $x$ & $x$ & $x$ & . \\
\hline CCPC 9 & . & . & &. & . &. & & . \\
\hline CCPC 10 & . & . & . & . & . & . & & . \\
\hline CCPC 11 & . & . & . & . & . & . & . & . \\
\hline CCPC 12 & . & . & . & . & . & . & . & . \\
\hline
\end{tabular}

Podemos observar na tabela que todas as 8 questões apresentaram minimamente a marcação em uma capacidade, o que segundo a classificação dada pelos colaboradores, quer dizer que todas são questões que demandam algumas capacidades do pensamento crítico para a sua resolução. As áreas de capacidades que apresentaram percentuais satisfatórios (CCPC 1, 2, 4, 6 e 8) foram as que requerem que o estudante analise argumentos apresentados, faça e avalie deduções por meio da interpretação de enunciados e atribua juízo de valor a uma determinada informação, considerando os fatos relevantes e a consequência para determinadas ações.

Após a confirmação de que as questões trabalhadas demandam capacidades do pensamento crítico para sua resolução, partiremos agora para a análise de desempenho dos estudantes ingressantes e concluintes, afim de verificar quem apresenta um melhor percentual de desempenho na análise de três variáveis: variável curso (referente aos estudantes dos cursos de licenciatura e bacharelado em química), variável instituição (tipo de instituição que o aluno pertence, pública ou privada), variável escola (tipo de escola em que o aluno estudou ao longo do ensino básico, pública ou privada).

Como estamos tratando das questões de formação geral objetivas da prova ENADE2014, é válido ressaltar alguns aspectos referentes a essa variável de desempenho. Essa variável é representada no banco de dados disponibilizado pelo INEP por notas que são apresentadas com valores correspondentes a 0, 25, 50, 75 e 100, considerando que são 8 questões, o valor 50 corresponde aos alunos que acertaram 4 ou mais questões, sendo assim, consideraremos como estudantes que acertaram as questões, aqueles que apresentaram uma nota igual ou superior a 50.

Variável curso: para a realização desta análise fez-se uso do software R.64bit, em que foi obtido o número de alunos que atingiu cada uma das notas e a partir dele foi efetuado o teste de Qui-quadrado. Na tabela 2, estão representadas as 5 notas que compõe a variável de desempenho, assim como o número de estudantes em cada curso que pode atingir cada uma das notas possíveis. A tabela 2 auxiliará na discussão do percentual de desempenho dos estudantes na variável curso. 
Tabela 2: Número de alunos ingressantes e concluintes dos cursos de licenciatura e bacharelado em química que obtiveram cada uma das 5 notas nas questões objetivas de formação geral.

\begin{tabular}{|c|c|c|c|}
\hline & Notas & Bacharelado & Licenciatura \\
\hline \multirow{5}{*}{ 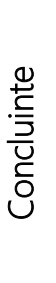 } & 0 & 16 & 15 \\
\hline & 25 & 102 & 270 \\
\hline & 50 & 399 & 725 \\
\hline & 75 & 531 & 703 \\
\hline & 100 & 99 & 112 \\
\hline \multirow{5}{*}{ 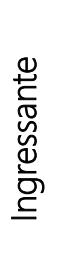 } & 0 & 1 & 6 \\
\hline & 25 & 18 & 58 \\
\hline & 50 & 59 & 153 \\
\hline & 75 & 93 & 146 \\
\hline & 100 & 8 & 18 \\
\hline
\end{tabular}

Como estamos considerando acerto, apenas aqueles estudantes que obtiveram uma pontuação igual ou superior a 50, temos que os estudantes concluintes do bacharelado, estudantes concluintes da licenciatura, estudantes ingressantes do bacharelado e estudantes ingressantes da licenciatura, apresentam os seguintes percentuais de acertos nas questões respectivamente, $90 \%, 84 \%, 89 \%$ e $83 \%$.

Para efetuar o teste de qui-quadrado, consideramos as seguintes combinações (Tabela 3) de dados obtidos a partir da tabela 3.

Tabela 3: combinações que podem ser realizadas para a variável 1.

\begin{tabular}{|c|c|c|c|c|}
\hline \multicolumn{4}{|c|}{ Comparações que podem ser feitas } & \multirow{2}{*}{$\frac{p \text {-valor }}{0,5576}$} \\
\hline 1 & EIL & $x$ & $E C L$ & \\
\hline 2 & EIB & $x$ & ECB & 0,2308 \\
\hline 3 & EIL & $x$ & EIB & 0,03434 \\
\hline 4 & $E C L$ & $x$ & $E C B$ & $1,15.10^{-05}$ \\
\hline
\end{tabular}

Notas: EIL: estudantes ingressantes da licenciatura; ECL: estudantes concluintes da licenciatura; EIB: estudantes ingressantes do bacharelado; ECB: estudantes concluintes do bacharelado.

Quando efetuamos as combinações da variável de desempenho com a variável curso e efetuamos o teste de qui-quadrado com o auxílio do software R, são gerados números de p-valor, que demonstram se há diferença estatística significativa ou não entre a comparação que é realizada. É importante mencionar que quando o p-valor apresentado é igual ou inferior a 0,05, o hipótese testada é aceita e é considerado que não há diferença estatística, já quando o p-valor apresentado é superior a 0,05, a hipótese é negada e há diferença estatisticamente significativa.

$\mathrm{Na}$ análise comparativa entre o subgrupo dos alunos dos cursos de bacharelado e licenciatura tanto de instituições públicas quanto privadas, chegou-se aos seguintes resultados: das 4 comparações realizadas, apenas duas delas demonstram pelo valor do qui-quadrado que há uma diferença estatística significativa, nos casos das comparações EIL versus ECL e EIB versus ECB, os p-valores apresentados foram respectivamente 0,5576 e 0,2308 . Observando os percentuais referentes a cada um dos casos, pode-se notar que os 
estudantes concluintes tanto da licenciatura, quanto do bacharelado apresentam um desempenho superior, aos demais.

Variável instituição: as comparações realizadas nessa variável seguiram os mesmos procedimentos adotados na variável curso. O número de alunos que obteve cada uma das notas possíveis, está apresentado na tabela 4. É válido mencionar que os valores apresentados na tabela, foram utilizados para efetuar as comparações e os testes de quiquadrado para a variável instituição.

Assim como no caso da variável anterior, consideramos como estudantes que acertaram as questões, aqueles que apresentaram uma pontuação das questões igual ou superior a 50. O percentual de acerto das questões é de $81 \%$ quando os estudantes são ingressantes do curso de licenciatura de instituições privadas, $82 \%$ quando os estudantes são concluintes do curso de licenciatura de instituições privadas, 90\% é o percentual de estudantes ingressantes dos cursos de licenciatura de instituições públicas, que obtiveram o acerto nas questões, 85\% o dos estudantes concluintes dos cursos de licenciatura de instituições públicas. Para o curso de bacharelado foram obtidos os seguintes percentuais: 84\% para os estudantes ingressantes de instituições privadas, 89\% para os estudantes concluintes de instituições privadas, 98\% para os estudantes ingressantes de instituições públicas e $90 \%$ para os estudantes concluintes de instituições privadas.

Para efetuar o teste de qui-quadrado da variável instituição foram realizadas as comparações que estão apresentadas na tabela abaixo. Na tabela 5, além das combinações propostas, estão apresentados os respectivos p-valor calculados.

Tabela 5: comparações que foram realizadas para a variável instituição e o p-valor associado a cada uma delas.

\begin{tabular}{llcll}
\hline & \multicolumn{3}{c}{ Comparações } & p-valor \\
\hline 1 & EIL_PI & $\times$ & ECL_PI & 0,9382 \\
\hline 2 & EIL_PU & $\times$ & ECL_PU & 0,2199 \\
\hline 3 & EIB_PI & $\times$ & ECB_PI & 0,04578 \\
\hline 4 & EIB_PU & $\times$ & ECB_PU & 0,2456 \\
\hline
\end{tabular}

Nota: EIL_PI: estudantes ingressantes dos cursos de licenciatura que eram de instituições privadas; ECL_Pl: estudantes concluintes dos cursos de licenciatura que eram de instituições privadas; EIL_PU: estudantes ingressantes dos cursos de licenciatura o que eram de instituições públicas; ECL_PU: estudantes concluintes dos cursos de licenciatura que eram de instituições públicas; EIB_Pl: estudantes ingressantes dos cursos de bacharelado que eram de instituições privadas; ECB_PI: estudantes concluintes dos cursos de bacharelado

que eram de instituições privadas; EIB_PU: estudantes ingressantes dos cursos de bacharelado que eram de instituições públicas; ECB_PU: estudantes concluintes dos cursos de bacharelado que eram de instituições públicas.

Dentre as 4 comparações que foram realizadas, apenas 1 delas apresentou um valor de qui-quadrado inferior a 0,05, sendo assim, as demais apresentaram uma diferença estatística significativas entre seus percentuais. Quando são comparados os dados referentes as instituições privadas, os alunos concluintes dos cursos de licenciatura apresentam um percentual de desempenho superior aos alunos ingressantes do mesmo curso, já quando se trata do desempenho dos estudantes do curso de bacharelado, segundo o valor de quiquadrado apresentado (menor que 0,05), não é observada uma diferença de desempenho estatisticamente significativa. Quando observamos os percentuais de desempenho considerando as instituições públicas, os estudantes ingressantes tanto do curso de 
licenciatura, quanto do curso de bacharelado apresentam um percentual de desempenho superior com relação aos estudantes concluintes do mesmo tipo de IES.

Variável escola: adotando-se os mesmos procedimentos das variáveis anteriores, foi obtido o número de estudantes e suas respectivas notas, dividindo desta vez, a análise pelo tipo de escola em que o estudante frequentou ao longo do seu ensino básico (tabela 6) e subsequentemente foi identificada a porcentagem de estudantes que responderam as questões de maneira correta.

Tabela 6: Notas dos estudantes ingressantes e concluintes dos cursos de bacharelado e licenciatura, separadas pelo tipo de escola em que o aluno estudou na educação básica.

\begin{tabular}{|c|c|c|c|c|c|}
\hline & & \multicolumn{2}{|c|}{ Escola privada } & \multicolumn{2}{|c|}{ Escola pública } \\
\hline & Notas & Bacharelado & Licenciatura & Bacharelado & Licenciatura \\
\hline \multirow{5}{*}{ 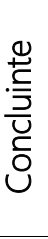 } & 0 & 5 & 11 & 4 & 3 \\
\hline & 25 & 8 & 118 & 42 & 83 \\
\hline & 50 & 20 & 299 & 151 & 232 \\
\hline & 75 & 52 & 291 & 192 & 200 \\
\hline & 100 & 6 & 40 & 33 & 32 \\
\hline \multirow{5}{*}{ 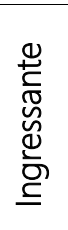 } & 0 & 0 & 3 & 1 & 3 \\
\hline & 25 & 1 & 24 & 9 & 17 \\
\hline & 50 & 10 & 66 & 16 & 48 \\
\hline & 75 & 8 & 62 & 33 & 38 \\
\hline & 100 & 1 & 9 & 4 & 3 \\
\hline
\end{tabular}

Aos dados da tabela 5 estão relacionados os seguintes percentuais: 86\% para estudantes concluintes dos cursos de bacharelado que eram de escolas privadas, 95\% é o percentual de acerto dos estudantes ingressantes dos cursos de bacharelado que eram de escolas privadas, $83 \%$ dos estudantes concluintes dos cursos de licenciatura que eram de escolas privadas, $84 \%$ dos estudantes ingressantes dos cursos de licenciatura que eram de escolas privadas, $89 \%$ dos estudantes concluintes dos cursos de bacharelado que eram de escolas públicas, $84 \%$ é o percentual dos estudantes ingressantes dos cursos de bacharelado que eram de escolas públicas, $84 \%$ daqueles que são concluintes dos cursos de licenciatura que eram de escolas públicas e $82 \%$ dos estudantes ingressantes dos cursos de licenciatura que eram de escolas públicas.

Assim como na variável instituição, foram feitas 4 comparações para a variável escola, que estão apresentadas na tabela 7 :

Tabela 7: comparações realizadas para a variável escola e o p-valor associado a cada uma delas

\begin{tabular}{llcll}
\hline \multicolumn{4}{c}{ Comparações } & p-valor \\
\hline 1 & EIL_EPI & $\times$ & ECL_EPI & 0,9929 \\
\hline 2 & EIL_EPU & $\times$ & ECL_EPU & 0,1573 \\
\hline 3 & EIB_EPI & $\times$ & ECB_EPI & 0,1302 \\
\hline 4 & EIB_EPU & $\times$ & ECB_EPU & 0,4586 \\
\hline \multicolumn{2}{r}{ Nota: EIL_EPI: estudantes ingressantes dos cursos de licenciatura que eram de escolas privadas; } \\
ECL_EPlestudantes concluintes dos cursos de licenciatura que eram de escolas privadas; EIL_EPU:
\end{tabular}

estudantes ingressantes dos cursos de licenciatura o que eram de escolas públicas;ECL_EPU: estudantes concluintes dos cursos de licenciatura que eram de escolas públicas; EIB_EPI: estudantes ingressantes dos

cursos de bacharelado que eram de escolas privadas; ECB_EPI: estudantes concluintes dos cursos de bacharelado que eram de escolas privadas; EIB_EPU: estudantes ingressantes dos cursos de bacharelado que eram de escolas públicas; ECB_EPU: estudantes concluintes dos cursos de bacharelado que eram de escolas públicas 
Todos os testes de qui-quadrado efetuados para essas combinações apresentaram um $p$-valor superior a 0,05. Sendo assim, todas as comparações realizadas apresentaram diferença estatística significativa em seus percentuais, destacando que quando se tratam de estudantes provenientes de escolas públicas, os estudantes concluintes tanto do curso de bacharelado quanto do curso de licenciatura, apresentam um desempenho superior. Já quando se trata de estudantes proveniente de escolas privadas, são os alunos ingressantes de ambos cursos que apresentam um desempenho superior.

De acordo com os dados apresentados pode-se inferir que na variável curso, os estudantes concluintes de ambos cursos apresentam desempenho superior, no entanto, quando abrangemos a nossa análise na variável instituição, quando os estudantes são pertencentes a IES privadas, os alunos concluintes da licenciatura apresentam um desempenho superior, já quando os estudantes são de IES públicas, os ingressantes apresentam um desempenho superior. Sobre esta variável, podem ser considerados três fatores, o primeiro deles é que, por conta do nível de dificuldade para o ingresso de estudantes no nível superior, há o investimento por parte dos estudantes em cursinhos, em um maior número de horas de estudo, que abrangem conteúdos de formação geral, por conta da diversidade de temas que podem ser tratados na redação do vestibular. Tal preparo dos estudantes pode ter influenciado no resultado apresentado e por conta disso os estudantes ingressantes tiveram um desempenho superior aos estudantes concluintes. Outro fator está relacionado a qualidade dos cursos, pela análise realizada, instituições privadas preparam melhor os seus alunos ao longo da sua formação no que se refere a questões de formação geral. Já as instituições públicas apresentam o resultado oposto, os conhecimentos relacionados a formação geral são abrandados ao longo da formação dos alunos. Com relação a variável escola, os estudantes de escolas públicas demonstram uma evolução nos seus conhecimentos de cunho geral ao longo da sua graduação, uma vez que os alunos que são concluintes dos cursos de licenciatura e bacharelado em química apresentam um desempenho superior aos ingressantes dos mesmos cursos. Os estudantes que vieram de escolas privadas, apresentam um desempenho superior quando são ingressantes, provavelmente pelo mesmo motivo mencionado na variável instituição, grande número de produção de redações e resolução de questões relacionadas a questões com caráter geral.

\section{Conclusões}

Analisando os dados apresentados, pode-se verificar que as variáveis de estudo apresentam influência no desempenho dos estudantes, pois de acordo com os dados apresentados pode-se inferir que na variável curso, os estudantes concluintes de ambos cursos apresentam desempenho superior, no entanto, quando abrangemos a nossa análise na variável instituição, quando os estudantes são pertencentes a IES privadas, os alunos concluintes da licenciatura apresentam um desempenho superior, já quando os estudantes são de IES públicas, os ingressantes que ganham destaque. Na variável escola, os estudantes de escolas públicas demonstram uma evolução nos seus conhecimentos de cunho geral ao longo da sua graduação, uma vez que os alunos que são concluintes dos cursos de licenciatura e bacharelado em química apresentam um desempenho superior aos ingressantes dos mesmos cursos. 
De maneira geral, pode-se concluir que os estudantes concluintes de instituições públicas demonstram certa deficiência no que se refere ao desempenho quando se tratam de questões que demandam capacidades do pensamento crítico relacionadas a analisar argumentos apresentados, fazer e avaliar deduções por meio da interpretação de enunciados e atribuir juízo de valor a uma determinada informação, considerando os fatos relevantes e a consequência para determinadas ações, uma vez que os estudantes ingressantes apresentam um desempenho superior, indicando que tais habilidade são atenuadas ao longo da formação. Quando se tratam de instituições privadas, essas habilidades são acrescentadas aos alunos concluintes dos cursos de licenciatura, evidenciando uma maior contribuição das instituições privadas na formação geral dos estudantes. Quando se trata da variável escola, é evidenciado uma maior influência no desempenho dos estudantes que são de escolas públicas, uma vez que são os concluintes que apresentam um desempenho superior aos demais nas questões de formação geral.

É importante mencionar que os dados apresentados pertencem apenas a amostra estudada nessa pesquisa, sendo assim, possíveis generalizações requerem expansão da amostra e outros estudos adicionais. 


\section{Referências}

BRASIL. Lei no 10.867, de 14 de abril de 2004.

BRASIL. Resolução $n^{0}$ 2, de $1^{\circ}$ de julho de 2015.

BRASIL. Portaria Inep no 255, de 02 de junho de 2014.

COLE, D. R. et al. Critical thinking skills in the International Baccalaureate's "Theory of Knowledge" subject: Findings from an Australian study. Australian Journal of Education, v. 59, n. 3, p. 247-264, 2015.

ENNIS, R. A logical basis for measuring critical thinking skills. Educational Leadership, 43 (2), 1985, 44- 48

NúÑEZ, J. C. et al. Subgroups of attributional profiles in students with learning dificulties and their relation to self-concept and acadmic goals. Learning Disabilities Research \& Practice, v. 20, n. 2, p. 86-97, 2005.

OLIVEIRA, F. E. M. SPSS Básico para Análise de Dados. Rio de Janeiro: Editora Ciência Moderna Ltda, 2007.

PRIMI, R. A validade do ENADE para avaliação da qualidade dos cursos de instituições de ensino superior. Projeto de Pesquisa. Itatiba: Universidade São Francisco, LabAPE, 2006.

PRIMI, R.; CARVALHO, L. F.; MIGUEL, F.K.; SILVA, M.C.R. Análise do funcionamento diferencial dos itens do Exame Nacional do Estudante (ENADE) de psicologia de 2006. Revista Psico-USF, v. 15, n. 3, p. 379-393, 2010.

TENREIRO-VIEIRA, C.; VIEIRA, R. M. Promover o Pensamento Crítico dos Alunos - Propostas Concretas para a Sala de Aula. Porto: Porto Editora, 2000.

VIEIRA, R. et al. Pensamento crítico na educação: perspectivas atuais no panorama internacional. CIDTFF, Universidade de Aveiro, 2014.

VIEIRA, R. M. Formação continuada de professores do $1 .^{\circ}$ e $2 .^{\circ}$ ciclos do Ensino Básico para uma educação em Ciências com orientação CTS/PC. Tese de doutoramento (não publicada), Universidade de Aveiro, 2003. 